MATEC Web of Conferences 6, 02007 (2013)

DOI: $10.1051 /$ matecconf $/ 20130602007$

(C) Owned by the authors, published by EDP Sciences, 2013

\title{
Improving the behavior of concrete exposed to fire by using an air entraining agent (AEA): Assessment of spalling
}

\author{
L. D'Aloia' ${ }^{1}$, F. Robert ${ }^{2}$, P. Rougeau², B. Moreau ${ }^{1}$, N. Flahault ${ }^{2}$ \\ and C. Collignon²
}

1 CETU/Ministry of Ecology, Bron, France

${ }^{2}$ CERIB: Epernon, France

\begin{abstract}
Several concrete mixes have been designed to evaluate the influence of an air entraining agent (AEA) on spalling. Tests have been performed under the ISO curve (occasionally under the $\mathrm{HC}_{\text {inc }}$ curve) on specimens of various sizes and shapes to assess spalling. Results were somehow erratic on the smallest specimens whereas the beneficial effect of the air-bubble network could be emphasized on slabs.
\end{abstract}

\section{INTRODUCTION}

Mix design of fire-resistant concrete can be performed by incorporating micro-polypropylene fibers or an air entraining agent (AEA) [1-4]. The latter option has been investigated in this study by evaluating the contribution of the air-bubble network to the behavior of concrete exposed to high temperatures. The assessment of spalling was essentially carried out under the ISO834 thermal loading (denoted ISO curve). Some tests were also performed under the increased hydrocarbon curve $\mathrm{HC}_{\mathrm{inc}}$ also called hydrocarbon modified curve, specifically used in tunnels [3]. Experiments were carried out on concrete specimens of various dimensions and shapes in order to better understand the influence of these test parameters on spalling results. Finally, transfer properties have been measured. A correlation has been investigated between the mechanical properties and the behavior of concrete exposed to fire.

\section{CONCRETE MIX DESIGN AND CHARACTERIZATION}

\subsection{Concrete mix design}

In the first step of this study (phase 1), a reference mix exhibiting a significant spalling and an average compressive strength of 60MPa, has been designed by using a cement-type: CEM I. No mineral addition was used to avoid any increase in the number of studied parameters. Besides, the main objective was to focus on concrete mixes liable to be used for tunnel concrete lining, i.e. concrete mixes exhibiting a moderate compressive strength (characteristic value lower than $45 \mathrm{MPa}$ ). Two mixes derived from the reference mix by adding AEA have been designed (two different dosages of the same AEA). These mixes (namely M60AEA1 and M60AEA2) exhibited a compressive strength of about 40 and 50MPa. All the concrete mix design parameters could not be kept constant when studying the influence of one of them. That is why the compressive strength changed when designing mixes with AEA. Keeping the compressive strength of concrete as a constant should have led to a change in the nature of cement (higher compressive strength of cement), a decrease in the water to cement ratio value to offset the effect of adding an AEA or even the use of mineral additions. Two additional reference mixes without

This is an Open Access article distributed under the terms of the Creative Commons Attribution License 2.0, which permits unrestricted use, distribution, and reproduction in any medium, provided the original work is properly cited. 
MATEC Web of Conferences

Table 1. Formulation and characterization of the 3 concrete mixes (tests performed on fresh concrete) - Phase 1 .

\begin{tabular}{|l|c|c|c|}
\hline For $1 \mathrm{~m} 3$ & M60 & M60AEA1 & M60AEA2 \\
\hline Cement: CEM I Le Teil $\left(\mathrm{kg} / \mathrm{m}^{3}\right)$ & 370 & 352 & 339 \\
\hline Coarse aggregates: Bathonian 6.3/14 $\left(\mathrm{kg} / \mathrm{m}^{3}\right)$ & 821 & 780 & 751 \\
\hline Sand: Bathonian 0/6.3 $\left(\mathrm{kg} / \mathrm{m}^{3}\right)$ & 1003 & 953 & 918 \\
\hline Superplasticizer $(\mathrm{BASF}$ Sky 537$)\left(\mathrm{kg} / \mathrm{m}^{3}\right)$ & 3.55 & 3.37 & 3.25 \\
\hline Air entraining agent $(\mathrm{AEA})$ BASF MicroAir $104\left(\mathrm{~kg} / \mathrm{m}^{3}\right)$ & 0 & 18.86 & 35.98 \\
\hline Total water & 193 & 184 & 177 \\
\hline w/c & 0.46 & 0.46 & 0.46 \\
\hline Slump $(\mathbf{c m})$ & $\mathbf{1 6}$ & $\mathbf{1 7 . 5}$ & $\mathbf{1 9}$ \\
\hline Air-entrained $(\mathbf{\%})$ & $\mathbf{1 . 3}$ & $\mathbf{4 . 9}$ & $\mathbf{7 . 2}$ \\
\hline Specific weight $\left(\mathbf{k g} / \mathbf{m}^{\mathbf{3}}\right)$ & $\mathbf{2 3 8 9}$ & $\mathbf{2 2 6 9}$ & $\mathbf{2 1 8 5}$ \\
\hline
\end{tabular}

Table 2. Characterization of the 3 concrete mixes (tests performed on hardened concrete, including transfer properties) - Phase 1 .

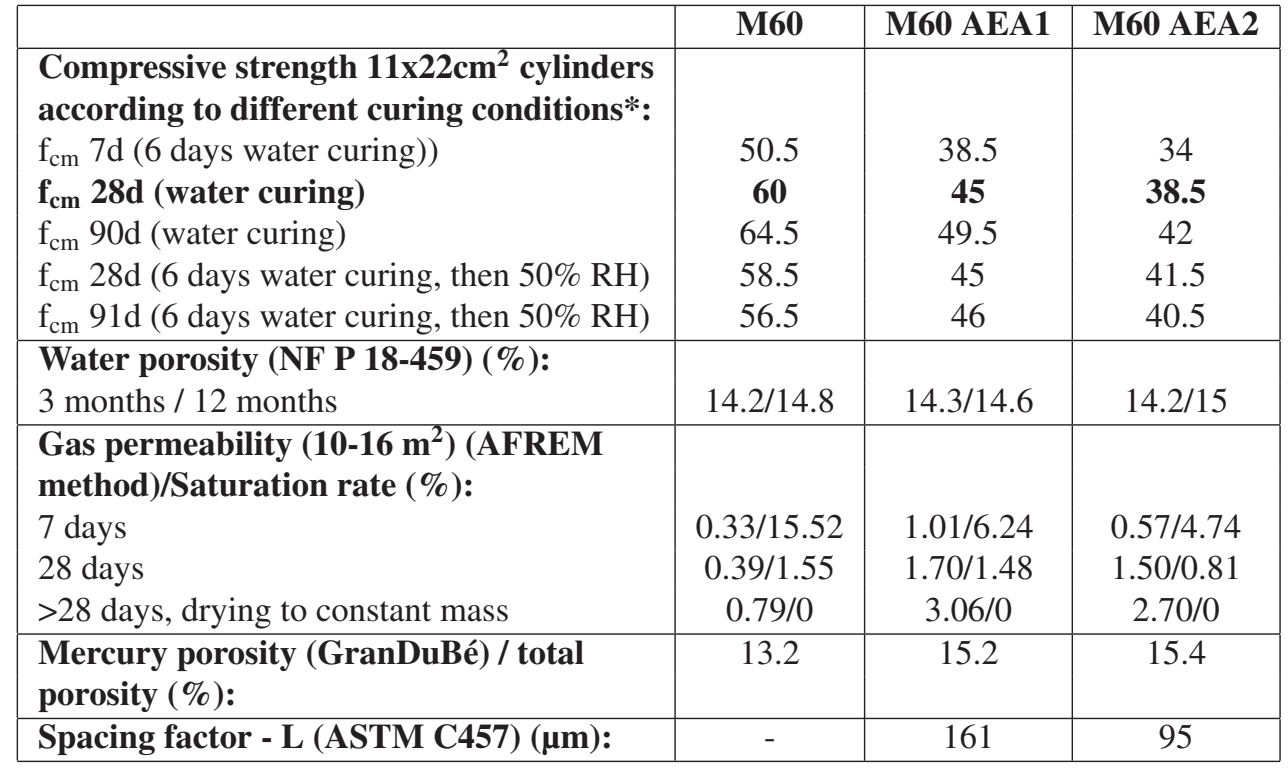

*: Removal from mold after 24 hours / RH: Relative Hygrometry.

AEA have been designed in the second step of this study (phase 2). Their compressive strengths are close to those of M60AEA1 and M60AEA2. Designing these mixes (namely M52 and M43) enabled to distinguish both the contribution of the air-bubble network and that of a change in the paste porosity induced by an increase in the water to cement ratio (w/c).

\subsection{Characterization of concrete mixes designed in phase 1}

The main features of concrete mixes have been measured. Slump test, air content and specific weight have been measured on fresh concrete whereas 28-day and 90-day strengths, mercury porosimetry, water porosity, gas permeability and spacing factor have been measured on hardened concrete. Results are shown in Tables 1 and 2 and also in Figure 1.

On the basis of these results, as it could be expected, the following conclusions could be drawn:

- The greater the dosage of AEA, the lower the spacing factor: $161 \mu \mathrm{m}$ for M60AEA1 and $95 \mu \mathrm{m}$ for M60AEA2; 

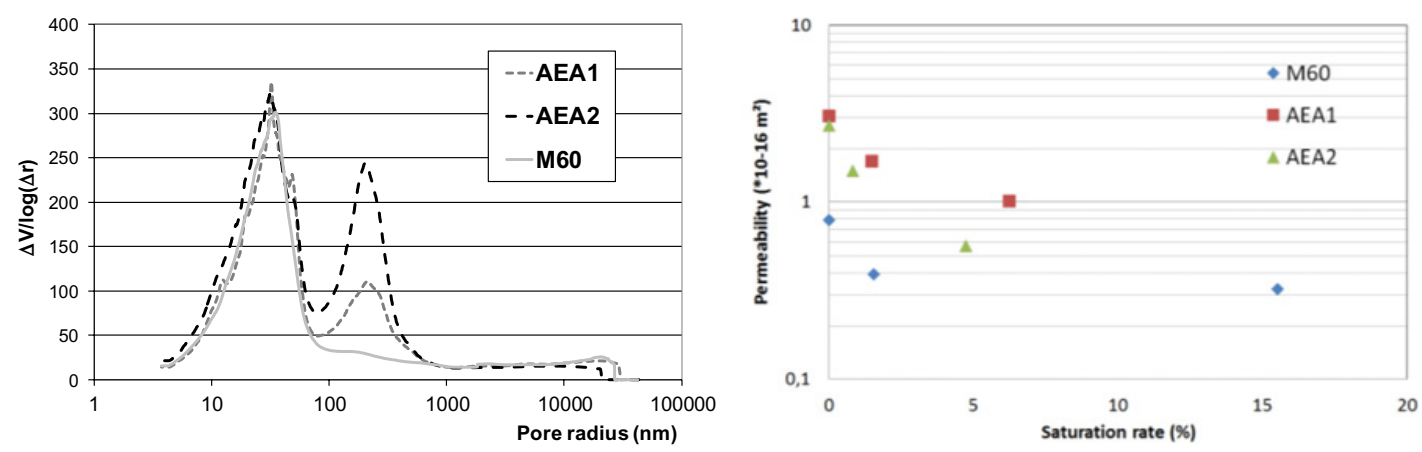

Figure 1. Gas permeability according to the saturation rate (on the left) and pore size distribution (mercury porosimetry) (on the right) for the 3 concrete mixes.

Table 3. Main features of the 5 concrete mixes - Phase 2 .

\begin{tabular}{|l|l|l|l|l|l|}
\hline & M60 & M60AEA1 & M60AEA2 & M43 & M52 \\
\hline w/c & 0.46 & 0.46 & 0.46 & 0.62 & 0.55 \\
\hline Slump (cm) & 17 & 10 & 20 & 12 & 14 \\
\hline Air-entrained (\%) & $\mathbf{1 . 6}$ & $\mathbf{5 . 5}$ & $\mathbf{8 . 5}$ & $\mathbf{1 . 6}$ & $\mathbf{1}$ \\
\hline $\mathrm{f}_{\mathrm{cm}}$ 7 days (6 days water curing) & 54.5 & 41.0 & 32.5 & 34.0 & 42.5 \\
\hline $\mathbf{f}_{\mathrm{cm}} \mathbf{2 8}$ days (water curing) & $\mathbf{6 4 . 5}$ & $\mathbf{4 7 . 0}$ & $\mathbf{3 9 . 0}$ & $\mathbf{4 4 . 5}$ & $\mathbf{5 4 . 0}$ \\
\hline $\begin{array}{l}\mathrm{f}_{\mathrm{cm}} \text { 98+1 days }(6 \text { days water curing, } \\
\text { then 50\% } \mathrm{RH})\end{array}$ & 64 & 48 & 38 & 49 & 53 \\
\hline
\end{tabular}

Removal from mold at 24 hours / Compressive strength measured on $11 \times 22 \mathrm{~cm}^{2}$ cylinders $(\mathrm{MPa})$.

- The greater the dosage of AEA, the lower the compressive strength: 60MPa for the reference mix M60 compared with 45 and $38.5 \mathrm{MPa}$ for the two mixes with AEA;

- The permeability of concrete mixes designed with AEA is greater than that of the reference mix M60 (Fig. 1).

Moreover, the measured water porosities are very similar, which is probably due to the fact that vacuum saturation did not enable to saturate the pores corresponding to air-entrained. Hence, the water porosities obtained do not therefore take into account the porosity corresponding to the effect of the AEA. Finally, the measurements carried out by mercury intrusion show a difference between the distribution of the M60 pore size and that of the other two concrete mixes.

\subsection{Characterization of concrete mixes designed in phase 2}

The main physical and mechanical features obtained in this second phase of the study are shown in Table 3 for the 5 mixes.

\section{ASSESSMENT OF SPALLING}

\subsection{Phase 1: ISO and $\mathrm{HC}_{\text {inc }}$ tests performed on small specimens (cylinders, small slabs and prisms)}

\section{ISO TEST:}

Experiments on concrete specimens of various dimensions and shapes have been carried out under high temperatures during the first step of this study. This has enabled to evaluate the possibility to measure 


\section{MATEC Web of Conferences}
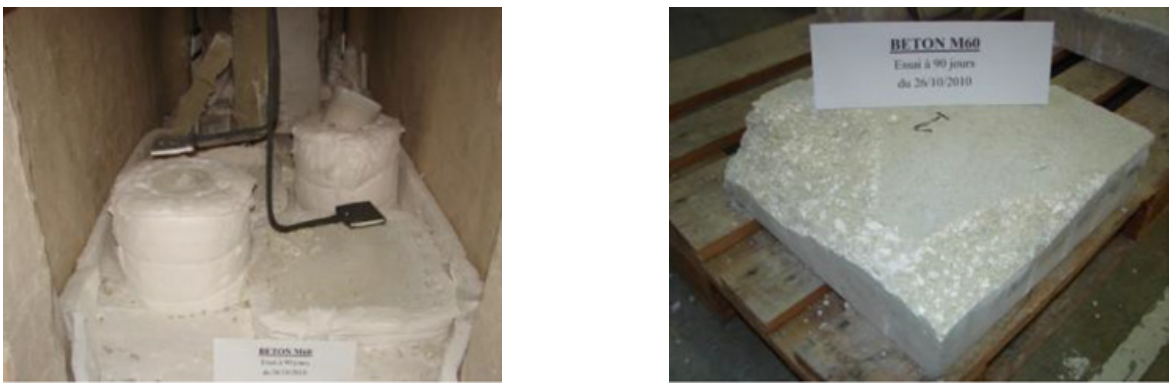

Figure 2. Cylinders and small slabs after ISO test (M60).


Figure 3. Photographs of prisms when getting them out from the furnace (ISO test: M60, M60AEA1 and M60AEA2).

concrete spalling by performing tests on specimens of limited dimensions $(16 \times 32 \mathrm{~cm}$ cylinders, $40 \times 40 \times 10 \mathrm{~cm}$ small slabs exposed on one side (Fig. 2) and $30 \times 30 \times 75 \mathrm{~cm}$ prisms exposed on 4 sides). Cylinders and small slabs were exposed under both $\mathrm{ISO}$ and $\mathrm{HC}_{\mathrm{inc}}$ curves. Prisms were only exposed to the ISO curve. The results obtained on cylinders and small slabs turn out to be of little use due to heterogeneous or inconsistent results. Although these results were difficult to analyses, conclusive results were obtained on prisms. The beneficial effect of adding an AEA on the behavior of concrete exposed to fire could be highlighted by analyzing tests performed on the largest specimens (Fig. 3). The water content of all concrete mixes was similar and less than $5 \%$ at the age of test (90 days). It should be noted that one of the M60 cylinders broke in two during the test.

After testing (Fig. 3), one can observe that large pieces of concrete have broken off from the edges of the M60 prism and reinforcement is visible (corner spalling). The M60AEA1 prism has shown limited corner spalling and reinforcement is not visible. Finally, no spalling has been observed on the M60AEA2 prism.

Mass loss during testing is lower for the M60AEA2 prism (Fig. 4). The M60 and M60AEA1 prisms have lost an edge between the $9^{\text {th }}$ and $14^{\text {th }}$ minute. The evolution of the mass loss of the M60 and M60AEA1 prisms is identical until the $71^{\text {th }}$ minute when the M60 prism loses large concrete pieces at the top of one side.

One can note that a few days after the end of test, the concrete surfaces exposed to fire are covered with lime. This white-colored powdery material is the result from the thermal decomposition of calcareous aggregates $\left(\mathrm{CaCO}_{3} \rightarrow \mathrm{CaO}+\mathrm{CO}_{2}\right)$. 
IWCS 2013

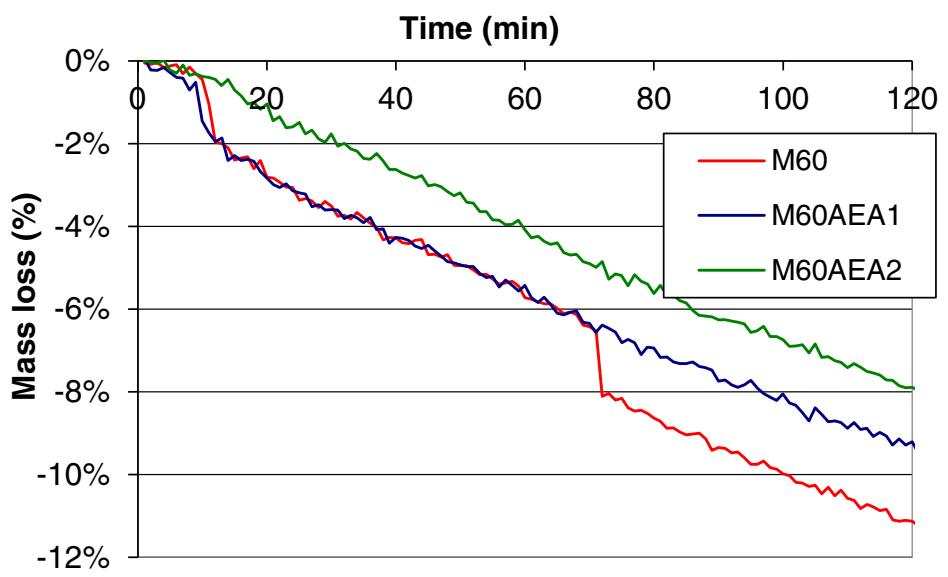

Figure 4. Mass loss of the 3 concrete prisms during the ISO test.
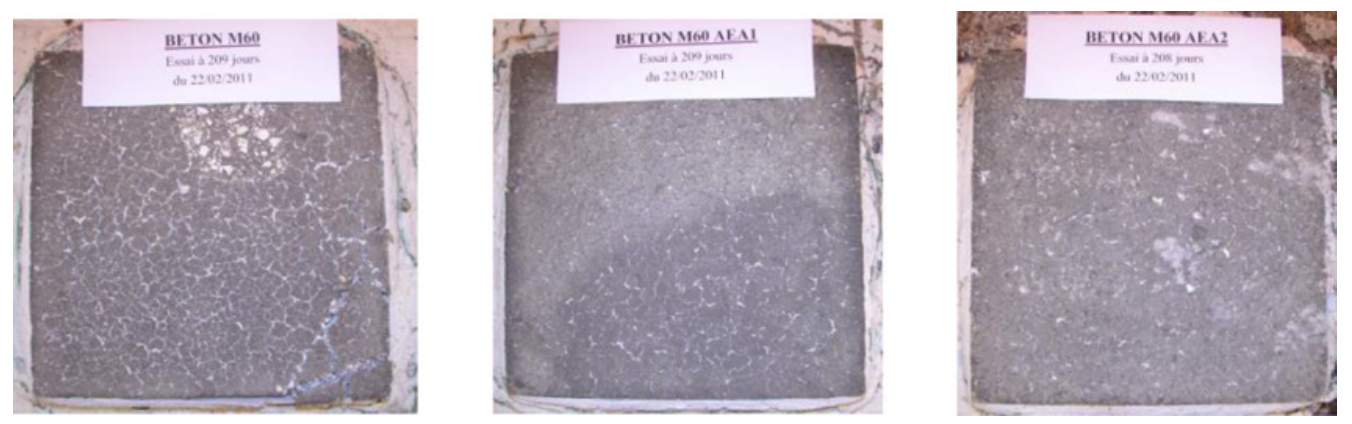

Figure 5. Photographs of small slabs after $\mathrm{HC}_{\mathrm{inc}}$ testing.

\section{HC inc TEST:}

Only the cylinders and small slabs were tested under the $\mathrm{HC}_{\mathrm{inc}}$ curve. The specimens were sealed after 90 days in order to keep their water content identical to that of the specimens tested under the ISO curve, i.e. slightly less than $5 \%$. The tests were carried out at 209 days.

Test results on small specimens were again inconsistent and revealed themselves of little use. All the cylindrical samples exhibited cracking on the face exposed to fire. Concerning small slabs, only the exposed face of the M60 slab has shown a significant spalling area of $11 \times 8 \mathrm{~cm}^{2}$ with a depth of $4 \mathrm{~mm}$. The M60AEA2 slab has shown some very superficial small flakes and no spalling has been observed on the M60AEA1 slab (Fig. 5). Moreover, the M60 and M60AEA1 slabs exhibited a denser surface cracking than the M60AEA2 slab. Finally, as for ISO tests, several days after the end of test, the concrete surfaces exposed to fire were covered by lime.

\subsection{Phase 2: ISO test on slabs}

In the second phase, results on the influence of AEA on spalling had to be confirmed at a larger scale on specimens of greater dimensions. Hence, ISO test has been carried out on $100 \times 170 \times 15 \mathrm{~cm}$ slabs in the CERIB's Prometheus furnace. Spalling has been measured according to a $2 \times 2 \mathrm{~mm}$ grid applied on the face exposed to fire. The tested specimens had an equivalent water content of about $4.5 \%$ at the age of test. The spalling results for the 5 mixes are shown in Table 4 . The pictures of 
Table 4. Spalling results measured after ISO test on $100 \times 170 \times 15 \mathrm{~cm}$ slabs.

\begin{tabular}{|l|c|c|c|c|c|}
\hline & M60 & M60 AEA1 & M60 AEA2 & M43 & M52 \\
\hline $\mathbf{f}_{\text {cm }}$ 28 days (water curing) & $\mathbf{6 4 . 5}$ & $\mathbf{4 7 . 0}$ & $\mathbf{3 9 . 0}$ & $\mathbf{4 4 . 5}$ & $\mathbf{5 4 . 0}$ \\
\hline $\mathrm{f}_{\mathrm{cm}}$ 98+1 days (6 days water curing, then 50\% RH) & 64 & 48 & 38 & 49 & 53 \\
\hline Sn = spalling area/surface exposed to fire $(\boldsymbol{\%})$ & $\mathbf{7 9 . 2}$ & $\mathbf{4 . 8}$ & $\mathbf{3 . 6}$ & $\mathbf{1 0 . 3}$ & $\mathbf{3 . 9}$ \\
\hline Pm = Average spalling depth (mm) & $\mathbf{1 3}$ & $\mathbf{1}$ & $\mathbf{1}$ & $\mathbf{5}$ & $\mathbf{2}$ \\
\hline
\end{tabular}

Removal from mold at 24 hours / Compressive strength measured on $11 \times 22 \mathrm{~cm}^{2}$ cylinders (MPa).

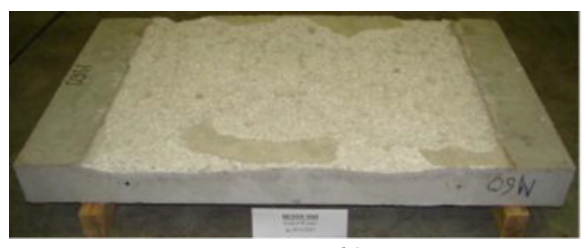

M60

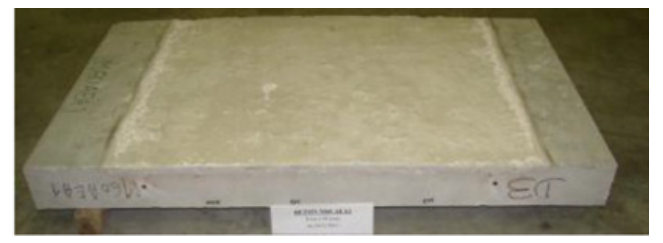

M60AEA1

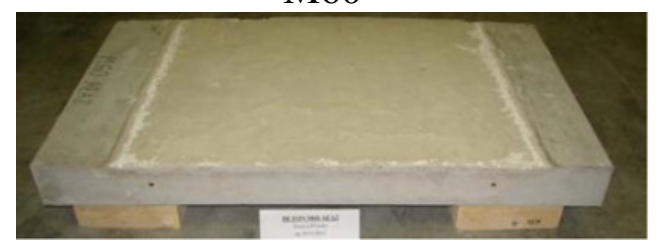

M60AEA2

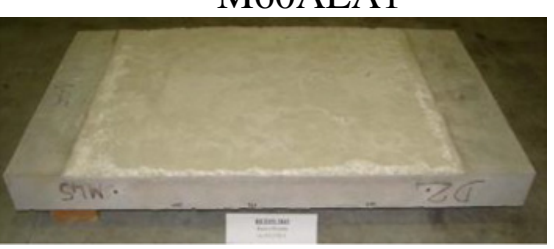

M43

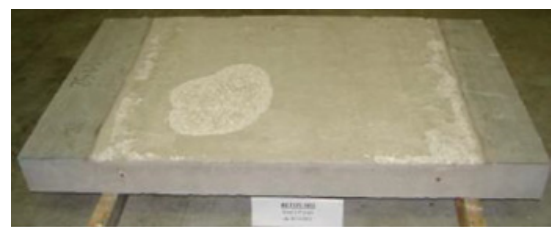

M52

Figure 6. Photographs of the 5 slabs after testing (ISO curve).

concrete surfaces exposed to fire are shown in Figure 6. Spalling with an average depth of $13 \mathrm{~mm}$ over a large area was obtained under the ISO curve on the M60 slab (about 80\% of the exposed area), whereas only large pieces of concrete have broken off from the edges of the prism exposed on 4 sides during the previous phase of the study. These initial findings show the influence of the shape, size and exposure of the specimen on the spalling measurement and therefore probably the effects induced by thermal and hydric gradients. Furthermore, spalling is equivalent and very limited on the M60AEA1 and M60AEA2 slabs. These results show the favorable effect of AEA on spalling without however showing any significant influence of its dosage. The decarbonation of calcareous aggregates leads to a slight swelling observable over almost the entire surface area of the slabs. The hydration of this quicklime leads to the formation of a powder of slaked lime (Fig. 6). This phenomenon should be distinguished from that of spalling since it occurs after the thermal stress, during the re-hydration of concrete. It depends on the characteristics of concrete (essentially on the mineralogical nature of aggregates).

Usually, spalling cannot be measured during testing. Insofar as the measured value is used for calculating the fire-resistance of a structure by accounting for spalling, it should at least be measured as soon as possible after the end of test and after cooling. When no spalling occurs, even if the mechanical features of concrete exposed to fire decrease, concrete continues to play its role of thermal insulation 


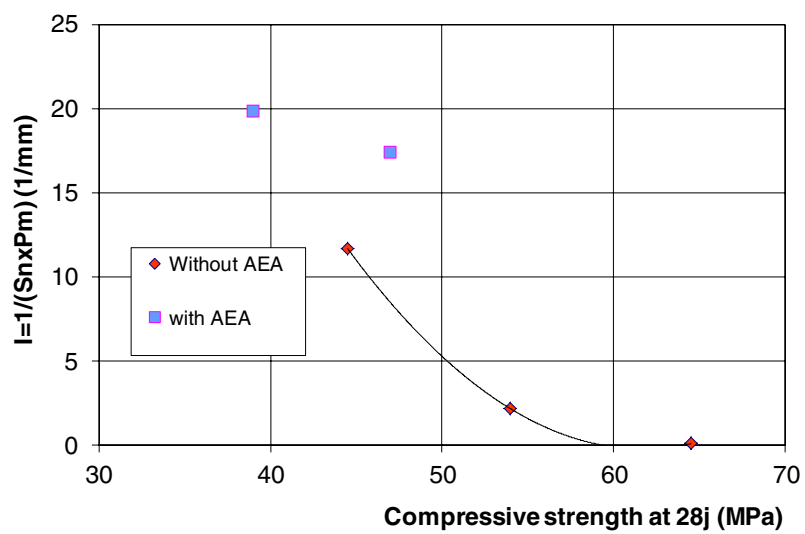

Figure 7. Influence of compressive strength on the risk of spalling.

with respect to reinforced bars. The difficulty however lies in separating phenomena when measuring spalling. Feedback shows distinct behaviors according to the concrete tested:

- Neat spalling caused by a thermo-hydro-mechanical phenomenon;

- Surface swelling caused by a chemical phenomenon depending on the mineralogical nature of aggregates;

- Melting of concrete and formation of a "crust" during cooling, which may separate from the specimen

These phenomena mean that the procedure for measuring the depth of spalling could be problematic and the measurement itself may turn out to be not relevant. One of the solutions may be to eliminate all the unstable fragments from the surface exposed to fire after testing and cooling. This is however no longer consistent with the use made of the measurement but nevertheless remains a safer solution with regards to the calculations.

Besides, at the end of the first phase of the study, the influence of a decrease in the compressive strength due to an increase into the w/c ratio or to the adding of an AEA was unclear. The design of two additional mixes M43 and M52 without AEA provides some clarification. In Figure 7 a relationship between the inverse of the product of the spalling depth by the relative spalling area and the compressive strength may be postulated within the range of strengths explored. It seems that for strengths below $40 \mathrm{MPa}$, the use of an AEA contributes nothing more than what could be obtained merely by increasing porosity (increase into the w/c ratio). On the other hand, for higher strengths it seems that the effect of the AEA is beneficial insofar as for the same mechanical strength the fire resistance appears greater. This trend however needs to be confirmed on a larger number of results.

\section{CONCLUSION}

The spalling of the studied concrete mixes remained moderate under the ISO curve. The spalling values measured on the largest slabs are lower than those measured on smaller concrete specimens. The behavior of the smallest specimens exposed to fire was somehow erratic. Thus, this study has enabled to underline the difficulty to assess the spalling of concrete exposed to fire. This can be attributed to the boundary conditions and to the presence of water gradients. In addition, results led to the conclusion that the procedure of spalling assessment has to be more precisely described in order to reflect all the phenomena at the basis of spalling including the influence of aggregates (decarbonation of limestone aggregates and re-hydration of quicklime at the surface of concrete specimen). By comparing M60AEA1 and M43 whose compressive strengths are equivalent, one can conclude on the influence of 


\section{MATEC Web of Conferences}

decreasing strength by increasing the water to cement ratio or by using an AEA. Results suggest that for a compressive strength lower than $40 \mathrm{MPa}$, the use of an AEA offers nothing more than what could be achieved by a simple increase in porosity resulting from an increase in the water to cement ratio. However, for higher strength, the effect of an AEA seems beneficial to the extent that, for the same strength, spalling resistance is higher for mixes containing air voids. Nevertheless, this trend has to be confirmed by carrying out more experiments. Some of the tests should be also performed under the higher thermal loading, i.e. under the $\mathrm{HC}_{\mathrm{inc}}$ curve. Finally, the influence of AEA should be compared with that of polypropylene fibers.

\section{References}

[1] Khoury G. A., Willoughby B. Polypropylene fibres in heated concrete. Part 1: Molecular structure and materials behaviour. Magazine of Concrete research 60 (2008) 125-136.

[2] Khoury G. A., Willoughby B. Polypropylene fibres in heated concrete. Part 1: Pressure relief mechanisms and modelling criteria. Magazine of Concrete research 60 (2008) 189-204.

[3] Féron C., Autuori P., Bessière C., Joyeux D. Vers des moyens de prévenir l'écaillage du béton en tunnel. Tunnels et Ouvrages Souterrains n 196 (2006) 228-235.

[4] Féron C. Prise en compte de l'incendie dans la conception des structures de tunnels. Congrès de l'AFTES, Monaco, 6-8 October 2008. 